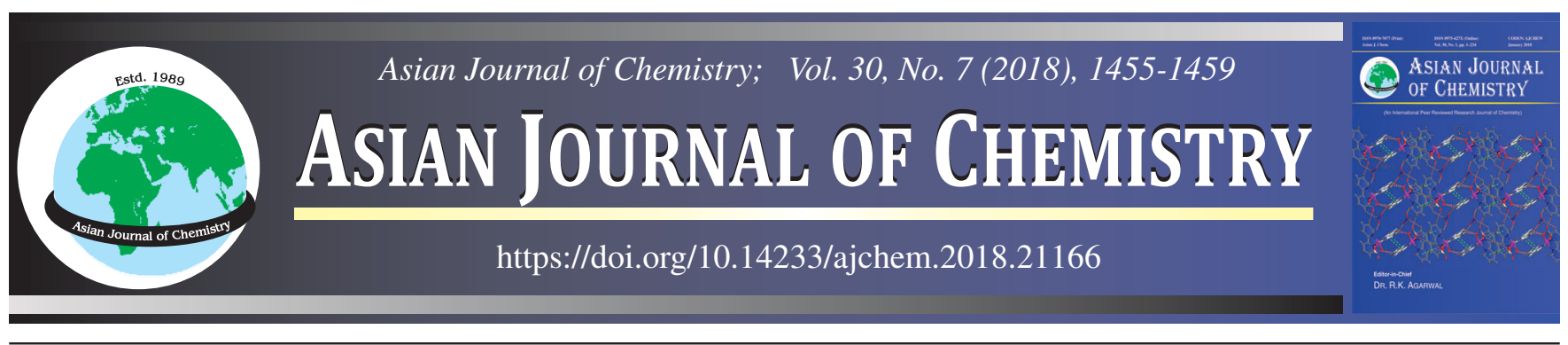

\title{
Diphenyldiselenide Mediated Synthesis of Copper Selenide Nanoparticles and their Poly(methyl methacrylate) Nanofibers
}

\section{S.B. SiвокоZA ${ }^{1}$, M.J. Moloto ${ }^{1, *}$, F. Mtunzi ${ }^{1}$ and N. Moloto ${ }^{2}$}

${ }^{1}$ Department of Chemistry, Vaal University of Technology, Private Bag X 021, Vanderbijlpark, 1900, South Africa

${ }^{2}$ School of Chemistry, University of the Witwatersrand, Private Bag 3, Wits, 2050, South Africa

*Corresponding author: Fax: +27 867563592; Tel: +27 169506689; E-mail: makwenam@vut.ac.za

Copper based chalcogenide nanoparticles have been synthesized using other methods or techniques. Less is reported on the use of metal complexes as single-source precursors for the synthesis of copper chalcogenide nanoparticles. Diphenyldiselenide is a stable organic source of selenide which is readily cleaved by using sodium borohydride to result in monodentate ligand to the copper metal. The complex is used as precursor to prepare the copper selenide nanoparticles under controlled conditions of hexadecylamine as a solvent and capping medium, time, concentration and temperature. The nanoparticles prepared are of well-defined optical properties and sizes lower than $5 \mathrm{~nm}$ which are spherical and highly monodispersed. The polymer fibres were prepared by using poly(methylmethacrylate) loaded with various mass $(0.2-1.8 \%)$ copper selenide to make nanofibres with diameters ranging from $1.95-14.65 \mu \mathrm{m}$. The thermal analysis reveals the increase in stability of the fibres as the amount of copper selenide nanoparticles is loaded.

Keywords: Copper selenide, Polymer nanofibers, Polymethylmethacrylate, Diphenyldiselenide.

\section{INTRODUCTION}

Copper selenide form group I-VI semiconductor with unique optical, electrical and biological properties [1-3]. Copper selenides are p-type semiconductor. Copper selenides are known for their application in solar cells, optical filter, highly efficient solar cells, thermoelectric converters, photo-detectors, electro conductive electrodes and microwave shielding coatings $[4,5]$. Copper selenides can exist in various stoichiometric forms such as $\mathrm{Cu}_{2} \mathrm{Se}, \mathrm{Cu}_{3} \mathrm{Se}_{2}, \mathrm{CuSe}$ and $\mathrm{CuSe}_{2}, \mathrm{Cu}_{5} \mathrm{Se}_{4}$ and $\mathrm{Cu}_{7} \mathrm{Se}_{5}$ [6] and non-stoichiometric $\mathrm{Cu}_{2-\mathrm{x}} \mathrm{Se}$ [7]. It has many crystalline forms such as cubic, hexagonal, tetragonal, orthorhombic and monoclinic [8-10]. Nanofibers incorporated with nanoparticles are known to have better properties such as physical, electrically, biological and optical compared to nanofibers without fillers [11]. The nanofillers are believed to significantly improve polymer properties $[12,13]$ and they have larger surface area which enables an applied load to be transferred through filler/matrix interface even at lower filler loading [14].

Electrospinning is a versatile and easy nanofabrication technique that is used to prepare non-woven mats of ultrafine fiber with diameter in the range of nanometer to few micro meters [15]. The nanofibers have high surface-to-volume ration, tunable porosity and malleability to conform over a wide variety of size and shape [16]. The nanofibers are widely applied in fields such as filtration, tissue engineering and sensory development and wound dressing [17]. In the electrospinning method, a high electric field is applied to viscous polymer solution held in the capillary tube and inducing a charge density on the liquid surface. Mutual charge repulsion causes a force directly opposite to the surface tension. When the electric field is sufficiently high, the surface of the solution in proximity of the tip of the capillary tube elongates and forms a Taylor cone. When a critical value of the electric field is reached, a repulsive electrical force overcomes the surface tension. The charged jet of the solution is ejected from the tip of the Taylor cone. As the jet accelerates and thins in the electric field, radial charges repulsion results in splitting of the primary jet into multiple filaments that is called spraying. The solvents evaporate and the filaments solidify in the collector. The filaments dry and form nanofibers. This study report the preparation of copper selenide nanoparticles and their incorporation into poly(methyl methacrylate) polymer to fabricate PMMA$\mathrm{CuSe}$ nanofiber using electrospinning technique.

\section{EXPERIMENTAL}

Copper chloride (97\%), methanol (99.5\%), hexadecylamine (HDA) (90\%), trioctylphosphine (TOP) (90\%), toluene $(99.5 \%)$ and poly(methylmethacrylate) $(\mathrm{M}=350000)$ were 
purchased from Sigma Aldrich. Sodium borohydride (95\%), dimethylformamide (DMF) $(99.5 \%)$ and diphenyldiselenide $(97 \%)$ were purchased from Merck. Ethanol (99.9 \%) and diethyl ether $(99 \%)$ were purchased from CC Imelmann and Rochelle Chemicals. These chemicals were used without any further purification.

Synthesis of complex from diphenyldiselenide ligand and copper salts: Diphenyldiselenide $(1.00 \mathrm{~g})$ was dissolved in ethanol $(20 \mathrm{~mL})$ and sodium borohydride $(0.25 \mathrm{~g})$ was added into the solution (Scheme-I). This solution was refluxed while stirring under inert environment until the yellow solution became colourless. The solution of copper chloride (1.00 g) dissolved in ethanol $(20 \mathrm{~mL})$ was added into this solution and refluxed for $4 \mathrm{~h}$. The resultant precipitates were filtered, washed with diethyl ether and allowed to dry in the desiccator. Anal. calcd. for $\mathrm{C}_{12} \mathrm{H}_{10} \mathrm{SeCuCl}_{2}: \mathrm{C}, 32.81 ; \mathrm{H}, 2.30$. Found: $\mathrm{C}, 32.53$ : $\mathrm{H}, 2.98$.

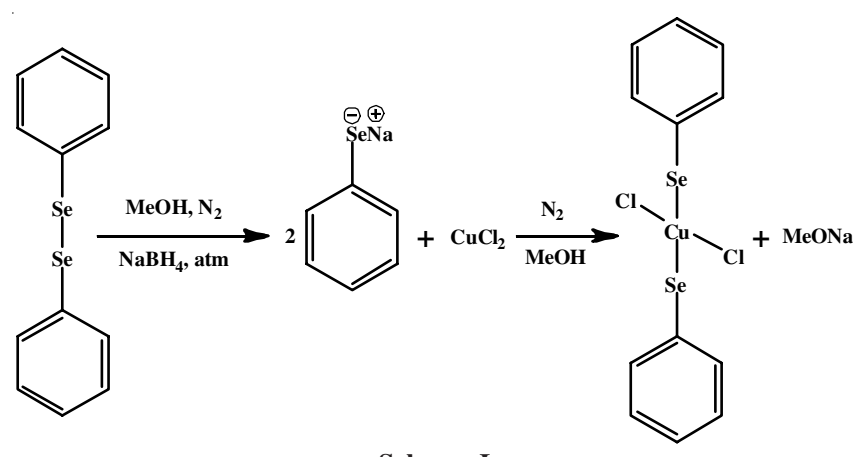

Scheme-I

Synthesis of copper selenide nanoparticles: Copper selenide nanoparticles was synthesized by thermal decomposition of complex (Scheme-II). An amount of the complex (1.0 g) was dissolved into trioctyphosphine (TOP) $(5 \mathrm{~mL})$. The solution was injected into hot hexadecylamine (HDA) $(5.0 \mathrm{~g})$ which was heated and maintained at $145^{\circ} \mathrm{C}$ under nitrogen atmosphere. This reaction was maintained at this temperature with constant stirring for $1 \mathrm{~h}$. Then, the solution was cooled to $70{ }^{\circ} \mathrm{C}$ and an excess of methanol was added. The precipitates formed were isolated by a centrifuge, washed with methanol three times to remove some of the capping agent and allowed to dry.

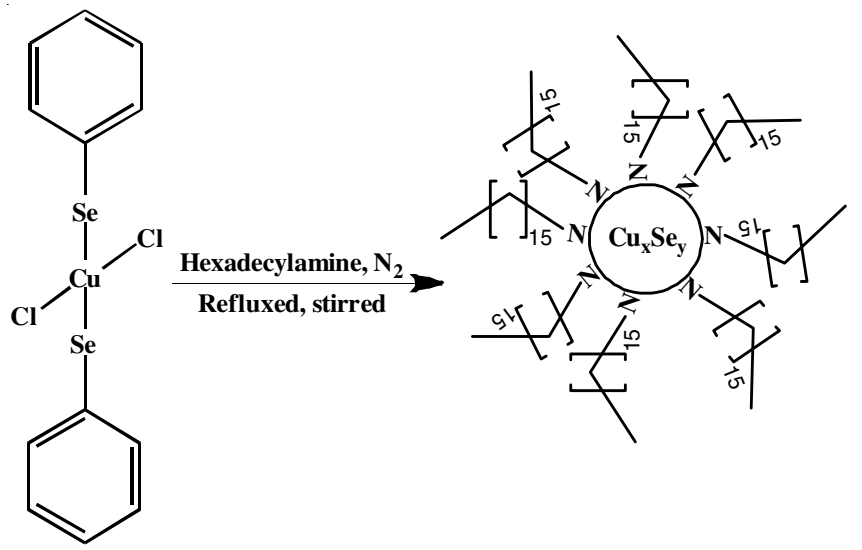

Scheme-II
Preparation of PMMA-CuSe nanofibers: Poly(methyl methacrylate) in tetrahydrofuran (PMMA/THF) $(2 \mathrm{~g}$ in $20 \mathrm{~mL}$ corresponding to $10 \mathrm{wt} \%$ ) solution were mixed for $12 \mathrm{~h}$ by stirring at room temperature. Various amounts of copper selenide nanoparticles $(0.04,0.12,0.2,0.28$ and $0.36 \mathrm{~g}$ corresponding to $0.2,0.6,1.0,1.4$ and $1.8 \mathrm{wt} \%$, respectively) were added and stirred for $12 \mathrm{~h}$. The PMMA/THF solution containing CuSe nanoparticles was loaded into a pasteur pipette. A copper wire was inserted into the polymer solution and connected to the positive electrode of high voltage. The negative electrode was connected to the plastic plate rapped with aluminum foil and used as a collector. The separation distance between the needle and collection plate and applied voltage were held constant at $20 \mathrm{~cm}$ and $20 \mathrm{kV}$, respectively. The electrospinning process was done in a horizontal mode in a fume hood at room temperature.

Characterization: Infrared spectra were recorded on FTIR Perkin Elmer 400 spectrometer. Spectra were collected over the range from 650 to $4000 \mathrm{~cm}^{-1}$. Thermogravimetric analysis was performed using Perkin Elmer Pyris 6 TGA under an inert atmosphere of dry nitrogen. The compounds were heated at 30 to $800^{\circ} \mathrm{C}$ at a heating rate of $10^{\circ} \mathrm{C} \mathrm{min}^{-1}$. Elemental analyses (C, H, N) were performed on a Thermo Scientific Flash 2000 CHNS-O analyzer fitted with auto sampler.

Absorption spectra of the nanoparticles were measured using Perkin Elmer Lambda 25 UV-VIS spectrophotometer in the spectral range of $190-900 \mathrm{~nm}$. The samples were placed in a quartz cuvette $(1 \mathrm{~cm}$ path length) with toluene as the solvent. Powder X-ray diffraction patterns of the samples were recorded using a Shimadzu XRD 700 X-ray diffractometer with $\mathrm{Cu} \mathrm{K}_{\alpha}$ radiation $(\lambda=1.54 \AA)$ under the conditions of $40 \mathrm{kV}$ and 40 $\mathrm{mA}$. The samples were mounted flat and scanned between $5^{\circ}$ and $90^{\circ}$ in a step size of $0.05^{\circ}$ with a count rate of $9 \mathrm{~s}$. Transmission electron microscope (TEM) analysis was performed using HITACHI JEOL $100 \mathrm{~S}$ operated at $80 \mathrm{kV}$. All samples were deposited over carbon-coated copper grids and allowed to dry. The fibrous mats were examined by scanning electron microscopy (SEM) (FEI Quanta ESEM). A small section of the mat was mounted to a metal sample stub using double stick electrical conductive carbon tape and the sample was sputter coated with gold.

\section{RESULTS AND DISCUSSION}

The fabrication of nanofibers with incorporation of nanoparticles has intensively being studied using electrospinning technique. The work describes copper selenide synthesized and characterized using a combination of techniques and their incorporation into solution to create polymer filled fibres using the electrospinning technique. Conditions such as concentration of copper selenide nanoparticles have been explored to measure the conductivity and viscosity influence on the polymer and its properties.

Fig. 1(a) show the absorption spectra of copper selenide nanoparticles. The absorption spectra show a band edge at $375 \mathrm{~nm}$. The spectra are blue shifted compared to their bulk counter parts, which have the band edge between $539 \mathrm{~nm}$ and $1240 \mathrm{~nm}$ depending on their stoichiometry [18]. The photoluminescence of copper selenide is shown in Fig. 1(b). Their 


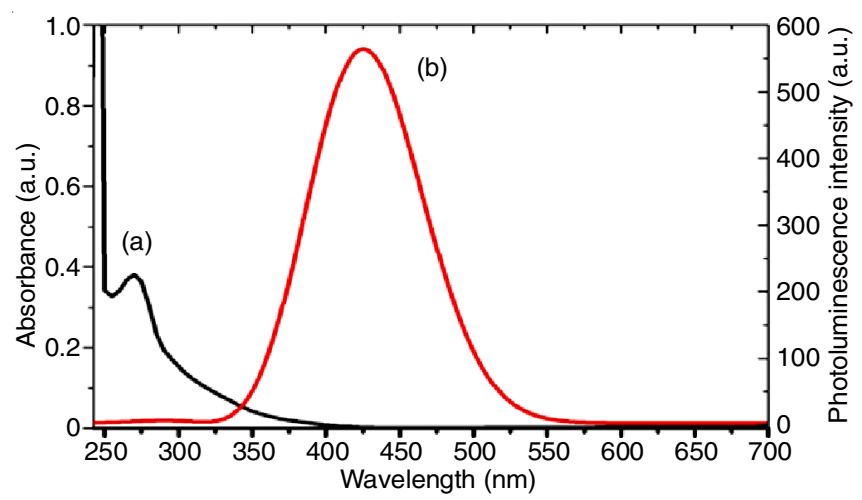

Fig. 1. Absorption (a) and emission (b) spectra of copper selenide nanoparticles prepared by using $1.0 \mathrm{~g}$ of the complex, $5 \mathrm{~g} \mathrm{HDA}$ at $145^{\circ} \mathrm{C}$ for $60 \mathrm{~min}$

photoluminescence spectra are red shifted from the absorption spectra with emission maxima located at about $425 \mathrm{~nm}$. The broad emission peak is associated with poly dispersed copper selenide nanoparticles.

TEM image of HDA-capped copper selenide nanoparticles is presented in Fig. 2. The image shows that the prepared copper selenide nanoparticles are spherical in shape. The particles size was found to be ranging between 1.4 to $4.7 \mathrm{~nm}$. The histogram shows size distribution of prepared copper selenide nanoparticles. The solution properties which include conductivity and viscosity of the poly(methyl methacrylate) impregnated with copper selenide were measured and listed in Table-1. The concentration of copper selenide nanoparticles (precipitates) were added in the solution of poly (methylmethacrylate) $(10 \%)$. The gradual increase in CuSe loading lead to an increase in viscosity of the solution due to the intramolecular and intermolecular interaction [18]. The diameter of PMMA-CuSe nanofibers were also increased as result of increased in viscosity. The conductivity was also measured and presented in Table-1. It was increased with the loading of CuSe. At $0.6 \%$ $\mathrm{CuSe}$ the conductivity was very high and as a result the diameter of nanofiber was significant decreased [18].

\begin{tabular}{cccc}
\multicolumn{4}{c}{ TABLE-1 } \\
\multicolumn{4}{c}{$\begin{array}{c}\text { MEASURE OF CuSe CONCENTRATION, VISCOSITY, } \\
\text { CONDUCTIVITY AND PMMA-CuSe NANOFIBERS }\end{array}$} \\
\hline $\begin{array}{c}\text { CuSe concen. } \\
(\mathrm{m} / \mathrm{v} \%)\end{array}$ & $\begin{array}{c}\text { Viscosity } \\
(\mathrm{mPa})\end{array}$ & $\begin{array}{c}\text { Conductivity } \\
(\mathrm{mS} / \mathrm{cm})\end{array}$ & $\begin{array}{c}\text { Nanofiber } \\
\text { diameter }(\mu \mathrm{m})\end{array}$ \\
\hline 0.2 & 205.27 & 29.2 & 8.91 \\
0.6 & 217.37 & 77.3 & 3.15 \\
1.0 & 234.81 & 79.6 & 11.41 \\
1.4 & 263.40 & 89.5 & 13.51 \\
1.8 & 256.89 & 109.0 & 14.65 \\
\hline
\end{tabular}

The PMMA mats were analyzed by FTIR spectroscopy to confirm the incorporation of CuSe in PMMA (Fig. 3). Fig. 3(a-f) shows that PMMA nanofibers have peaks at about 2994 and $2950 \mathrm{~cm}^{-1}\left(\mathrm{CH}_{3}\right.$ stretching vibration $), 1724 \mathrm{~cm}^{-1}(\mathrm{C}=\mathrm{O}$ stretching vibration), 1477,1446 and $1435 \mathrm{~cm}^{-1}$ (skeletal $\mathrm{CH}_{2}$ deformation), 1266 and $1239 \mathrm{~cm}^{-1}$ (C-C-O in the ester group) and 1190 and $1144 \mathrm{~cm}^{-1}$ (C-O-C of the methoxy group). For the PMMA nanofiber containing copper selenide nanoparticles new and shifted peaks was observed. Fig. 3 shows peaks at about 2994 and $2950 \mathrm{~cm}^{-1}$ and an extra peak at $2920 \mathrm{~cm}^{-1}$ $\left(\mathrm{CH}_{3}\right.$ stretching vibration $), 1724 \mathrm{~cm}^{-1}(\mathrm{C}=\mathrm{O}$ stretching vibration) and new peaks at 1681 and $1600 \mathrm{~cm}^{-1}$ (which becomes more intense as the copper selenide weight percent was increased), 1477,1446 and $1435 \mathrm{~cm}^{-1}$ (skeletal $\mathrm{CH}_{2}$ deformation, the peaks at 1477 and $1446 \mathrm{~cm}^{-1}$ intensities decreases as the weight percentages of copper selenide nanoparticles were gradually increased), 1268 and $1238 \mathrm{~cm}^{-1}$ (C-C-O in ester group) and 1190 and 1144 $\mathrm{cm}^{-1}$ (C-O-C of the methoxy group).
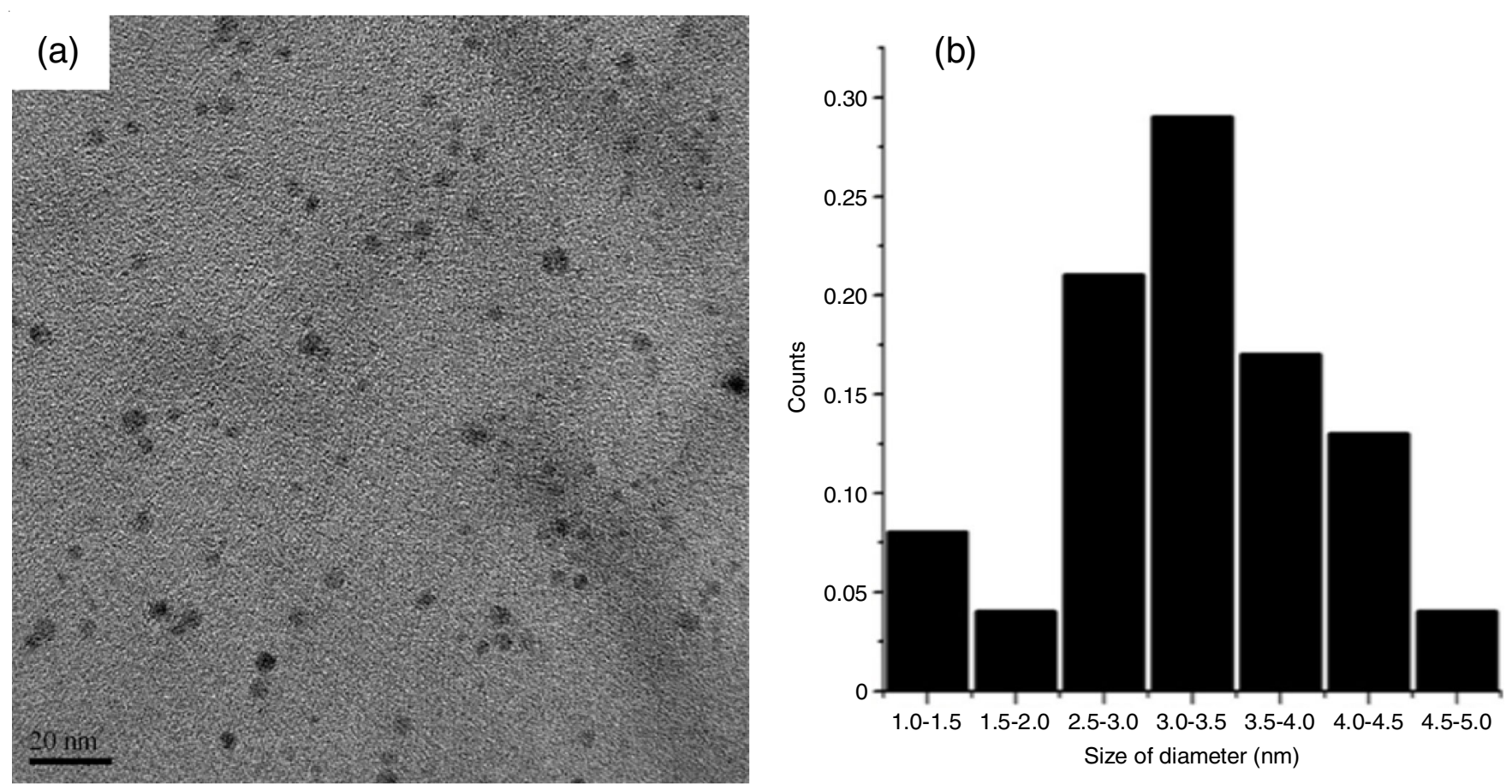

Fig. 2. TEM image (a) and their histogram (b) for the copper selenide nanoparticles prepared by using $1.0 \mathrm{~g}$ of complex, $5 \mathrm{~g}$ HDA at $145^{\circ} \mathrm{C}$ for $60 \mathrm{~min}$ 


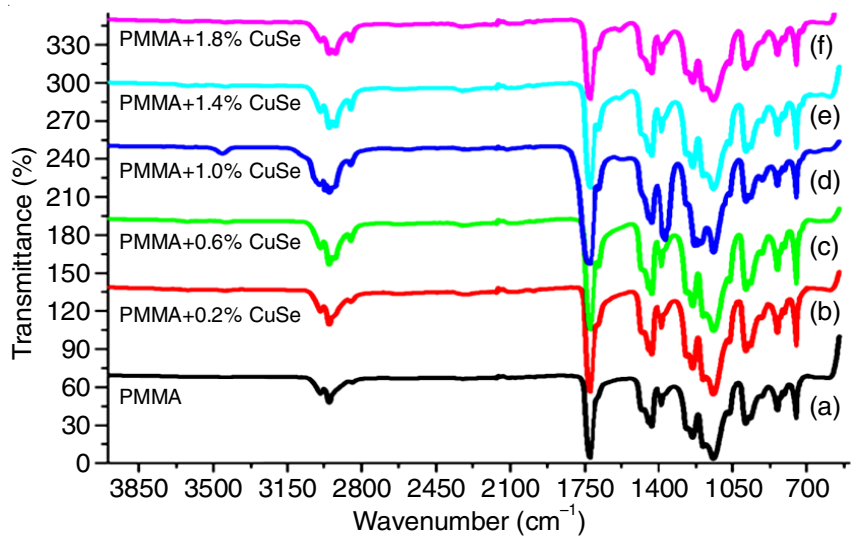

Fig. 3. FT-IR spectra of pure PMMA (a) and PMMA-CuSe (0.2-1.8) \% (bf) nanofibers

All TGA curves (Fig. 4(a-f)) show a single decomposition step between 250 and $450{ }^{\circ} \mathrm{C}$. The nanofibers become more stable as the loading of $\mathrm{CuSe}$ was increased. This composition shows some residue associated with $\mathrm{CuSe}$, while pure PMMA nanofiber decomposes completely. The increased thermal stability are a result of more interaction between the polymer and the nanoparticles.
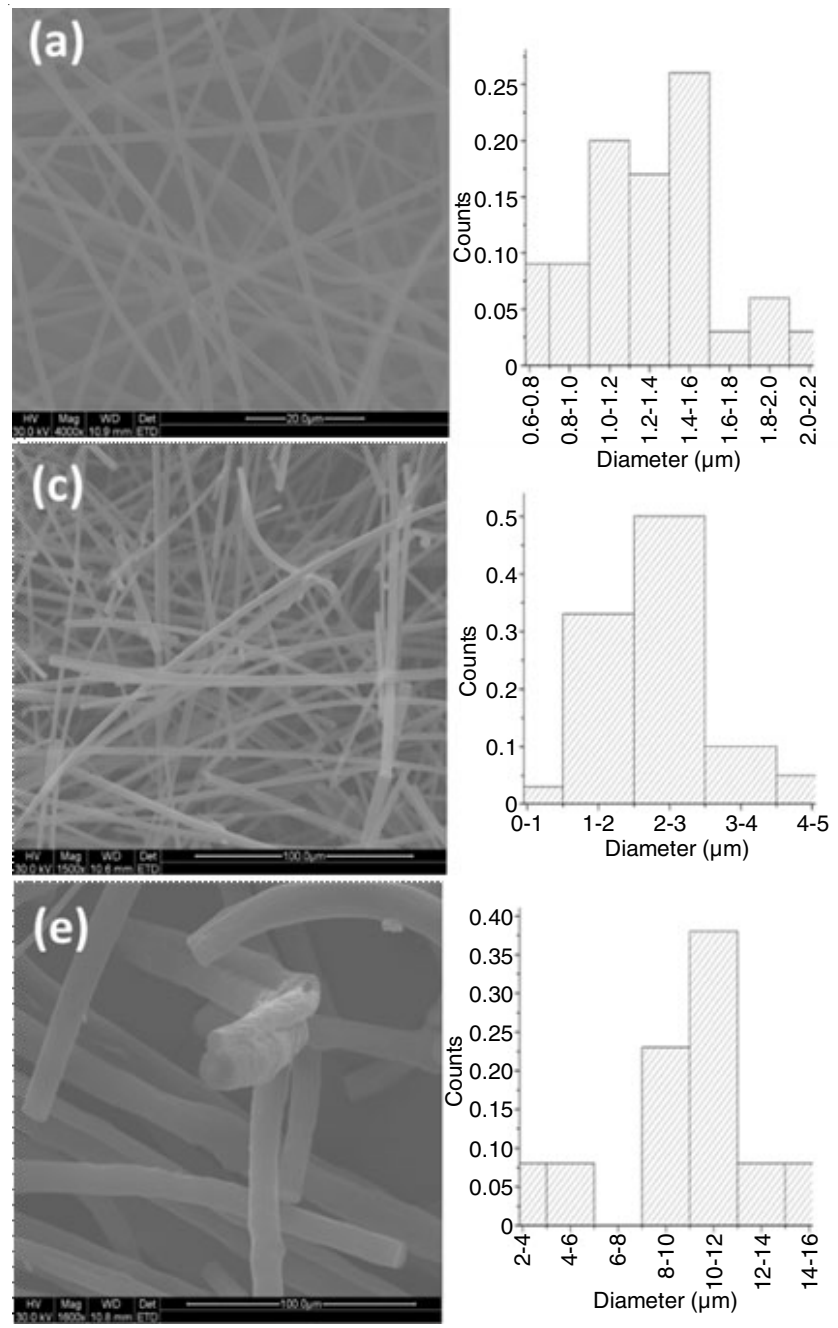

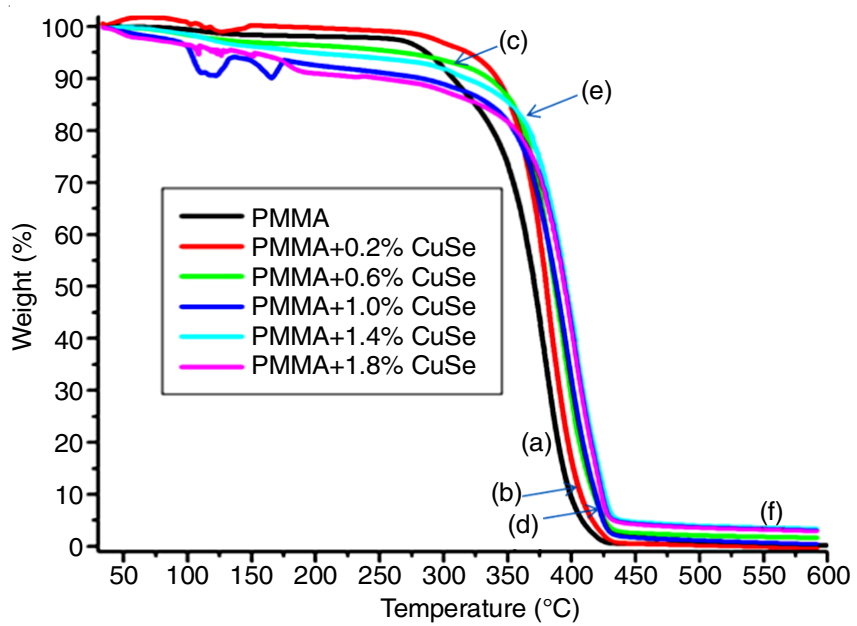

Fig. 4. Thermogravimetric analysis of PMMA(a) and PMMA-CuSe (b-f) nanofibers

The SEM images of PMMA-CuSe nanofibers are shown in Fig. 5. All images show uniform nanofibers with no beads. The PMMA nanofibers without copper selenide nanoparticles are uniform with smooth surface (Fig. 5(a)). The average diameter of these nanofibers is $1.41 \pm 0.54 \mu \mathrm{m}$. When $0.2 \%$ of
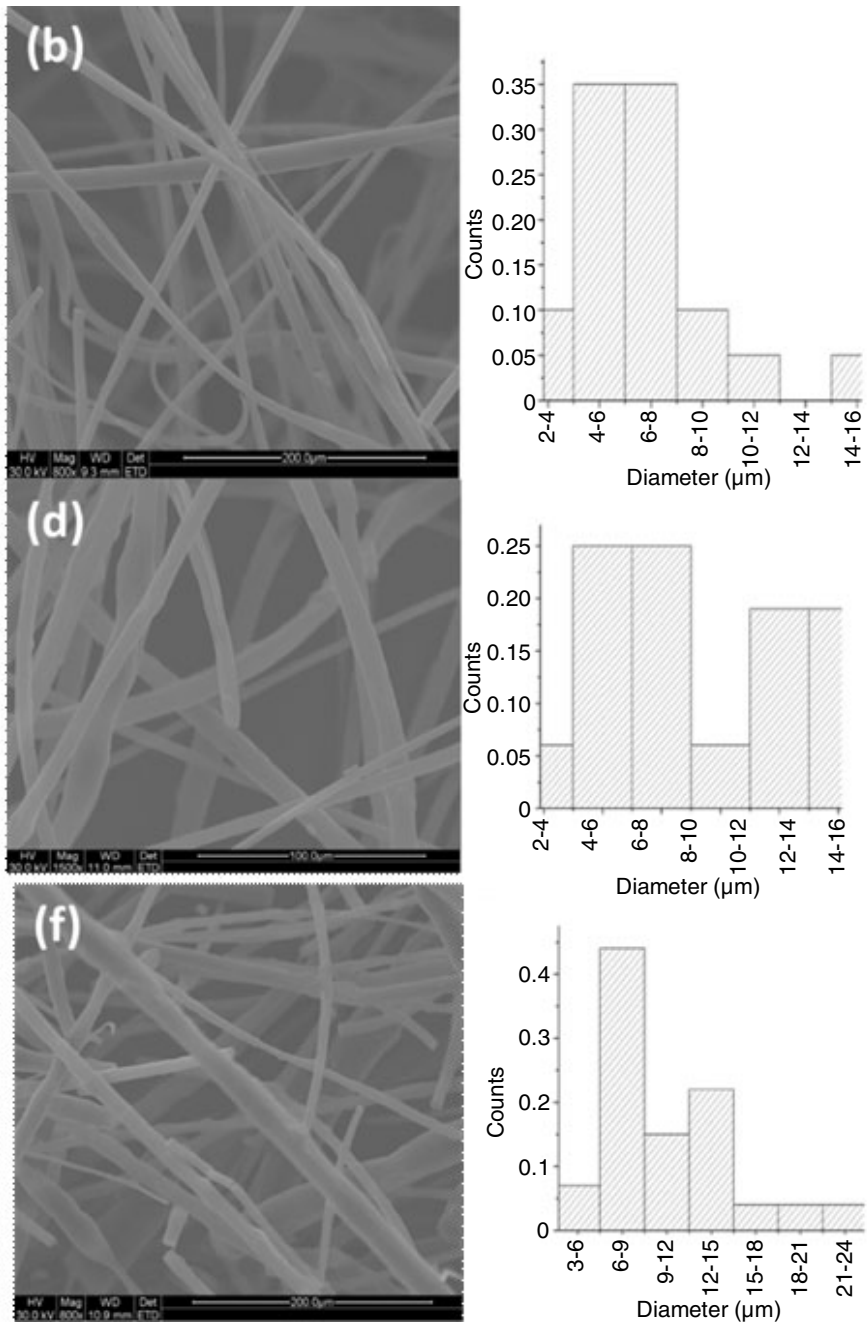

Fig. 5. SEM images of PMMA nanofibers: $10 \%$ PMMA (a), $10 \%$ PMMA + 0.2 \% CuSe (b), $10 \%$ PMMA + $0.6 \%$ CuSe (c), $10 \%$ PMMA $+1.0 \% \mathrm{CuSe}(\mathrm{d}), 10 \% \mathrm{PMMA}+1.4 \% \mathrm{CuSe}(\mathrm{e})$ and $10 \%$ PMMA + $1.8 \% \mathrm{CuSe}(\mathrm{f})$ 
CuSe nanoparticles is added to PMMA solution (Fig. 5(b)), the formed PMMA-CuSe nanofibers are uniform with rough surface. The roughness of their surface is associated with presence of $\mathrm{CuSe}$ nanoparticles. The average diameter of these nanofibers is $6.63 \pm 2.82 \mu \mathrm{m}$, a significant increase from PMMA nanofibers. The increase in diameter is a result of a uniform increase in viscosity of the solution (Table-1). When $0.6 \%$ of $\mathrm{CuSe}$ is loaded into PMMA solution, the formed PMMA-CuSe nanofibers have a diameter of $2.35 \pm 0.80 \mu \mathrm{m}$. This diameter is expected to increase uniformly as the viscosity of the solution is increased with loading of $\mathrm{CuSe}$ nanoparticles. But the conductivity is dramatically increased, this in turn resulted in a decrease in diameter of nanofibers (Table-1). When $1.0 \%$ of CuSe nanoparticles is loaded to PMMA solution, the formed PMMA-CuSe nanofibers have a diameter of $8.30 \pm 3.11 \mu \mathrm{m}$ [Fig. 5(d)]. The viscosity of the solution is increased uniformly which result to an increase in average diameter of PMMA$\mathrm{CuSe}$ nanofibers from to corresponding to the concentrations, respectively. When $1.4 \%$ of CuSe nanoparticles is loaded into PMMA solution, the formed PMMA-CuSe nanofibers have an average diameter of $10.18 \pm 3.33 \mu \mathrm{m}$. The diameter increased is associated with uniform increase in viscosity. When $1.8 \%$ of $\mathrm{CuSe}$ nanoparticles is loaded into PMMA solution, the formed PMMA-CuSe nanofibers have an average diameter of $10.25 \pm 4.40 \mu \mathrm{m}$. The increase in diameter is due to incense in viscosity of the solution.

\section{Conclusion}

The nanofibers of PMMA loaded with copper selenide were successfully prepared and characterized. The solution properties play a major part in the nanofibers preparation as demonstrated by viscosity measurements. The diameter of nanofibers increased with viscosity of solution. The FT-IR spectra shows that the poly(methylmethacrylate) used $\mathrm{C}=\mathrm{O}$ functional group to bind with the copper selenide nanoparticles. The SEM show smooth nanofibers with small pore as the concentration of copper selenide varied.

\section{ACKNOWLEDGEMENTS}

The authors acknowledge National Research Foundation, South Africa (NRF) and Vaal University of Technology for this work.

\section{REFERENCES}

1. J. Choi, N. Kang, H.Y. Yang, H.J. Kim and S.U. Son, Chem. Mater., 22, 3586 (2010); https://doi.org/10.1021/cm100902f.

2. I. Kreigel, J. Rodriguez-Fernandez, A. Wisnet, H. Zhang, C. Waurisch, A. Eychmuller, A. Dubavik, A. O. Goronov and J. Feldman, ACS Nano, 5, 4367 (2013); https://doi.org/10.1021/nn400894d.

3. P. Huang, Y. Kong, Z. Li, F. Gao and D. Cui, Nanoscale Res. Lett., 5, 949 (2010); https://doi.org/10.1007/s11671-010-9587-0.

4. R.A. Thakur, C.A. Florek, J. Kohn and B.B. Michniak, Int. J. Pharm., 364, 87 (2008); https://doi.org/10.1016/j.ijpharm.2008.07.033.

5. A. Toncheva, D. Paneva, N. Manolova, I. Rashkov, L. Mita, S. Crispi and D.G. Mita, Colloids Surf. A, 439, 176 (2013); https://doi.org/10.1016/j.colsurfa.2012.11.056.

6. V.M. Bhuse, P.P. Hankare, K.M. Garadkar and A.S. Khomane, Mater. Chem. Phys., 80, 82 (2003); https://doi.org/10.1016/S0254-0584(02)00306-1.

7. H.H. Chen, R.I. Zou, N. Wang, H.H. Chen, Z.Y. Zhang, Y.G. Sun, L. Yu, Q.W. Tian, Z.G. Chen and J.Q. Hu, J. Mater. Chem., 21, 3053 (2011); https://doi.org/10.1039/c0jm02637a.

8. M. Dhanam, P.K. Manoj and R.R. Prabhu, J. Cryst. Growth, 280, 425 (2005); https://doi.org/10.1016/j.jcrysgro.2005.01.111.

9. C. Levy-Clement, M. Neumann-Spallart, K.S.V. Santhanam and S.S. Haram, Thin Solid Films, 302, 12 (1997); https://doi.org/10.1016/S0040-6090(97)00021-7.

10. A. Pal, I. Halaciuga and D.V. Goia, J. Nanomater. Mol. Nanotechnol., 3, 1 (2014); https://doi.org/10.4172/2324-8777.1000149.

11. T.P. Mthethwa, M.J. Moloto, A. De Vries and K.P. Matabola, Mater. Res. Bull., 46, 569 (2011); https://doi.org/10.1016/j.materresbull.2010.12.022.

12. P. Kumar, K. Singh and O.N. Srivastava, J. Cryst. Growth, 312, 2804 (2010); https://doi.org/10.1016/j.jcrysgro.2010.06.014.

13. J. Zhu, Q. Li, L. Bai, Y. Sun, M. Zhou and Y. Xie, Chem. Eur. J., 18, 13213 (2012); https://doi.org/10.1002/chem.201200899.

14. H. Li, M. Zanella, A. Genovese, M. Povia, A. Falqui, C. Giannini and L. Manna, Nano Lett., 11, 4964 (2011) https://doi.org/10.1021/nl202927a.

15. L. Zou, B.-P. Zhang, Z.-H. Ge and L.-J. Zhang, J. Mater. Res., 29, 1047 (2014); https://doi.org/10.1557/jmr.2014.90.

16. D.W. Schaefer and R.S. Justice, Macromolecules, 40, 8501 (2007); https://doi.org/10.1021/ma070356w.

17. S. Lin, Q. Cai, J. Ji, G. Sui, Y. Yu, X. Yang, Q. Ma, Y. Wei and X. Deng, Compos. Sci. Technol., 68, 3322 (2008); https://doi.org/10.1016/j.compscitech.2008.08.033.

18. B. Duan, C. Dong, X. Yuan and K. Yao, Biomater. Sci. Polym. Edition, 15, 797 (2004); https://doi.org/10.1163/156856204774196171. 